\title{
Uma forma de educar na Escola Superior de Agricultura e Veterinária de Viçosa: a circulação de discursos higienistas e eugenistas na revista Seiva (1940 a 1948)
}

\author{
Pedro de Oliveira Milagres ${ }^{1}$ \\ Gabriel Gomes de Oliveira² \\ Anderson da Cunha Baía
}

Resumo

Esse estudo objetiva analisar saberes e práticas higienistas e eugenistas que circularam na revista Seiva, e que se tornaram parte do processo educativo da Escola Superior de Agricultura e Veterinária entre os anos de 1940 e 1948. Metodologicamente, está localizado no campo da História Cultural e utiliza dos ofícios do historiador, orientados por Certeau (2015). A eugenia circulou pela revista em suas conformações negativas e positivas, sendo esta última aliada aos preceitos higiênicos. O periódico visava incutir saberes modernos nos esavianos, tornando-os agentes do melhoramento rural, além de veicular saberes elementares aos sujeitos no campo. Considera-se que a revista Seiva se constituiu como parte do processo formativo dos esavianos e de sujeitos rurais, servindo a propósitos da Escola. Palavras-chave: Higienismo; Eugenia; ESAV; Agricultura; Espaço Rural; Interior.

\section{A form to educate in the Escola Superior de Agricultura e Veterinária de Viçosa: the circulation of hygienism and eugenics discuss on the periodical Seiva (1940-1948)}

\section{Abstract}

This paper aims to analyses knowledge and practices with hygienic and eugenic basis than circulated in a student periodical of the Escola Superior de Agricultura e Veterinária de Viçosa. They were constituted as a part of the educative process of the college between 1940 and 1948. Methodologically, this study was localized on the Cultural History and inspired by the historiographic operation of Certeau (2015). The results showed that the periodical circulated eugenics knowledge of negative and positive kinds, as well as knowledge and practice hygienics. The modern scientific knowledge received widespread support by periodical, putting habits of self-care and regeneration of the field in students and farmers. It concluded that the periodical Seiva was a part of the formative process of students and rural people, giving support for objectives of the College.

Keywords: Hygienism; Eugenics; ESAV; Agriculture; Rural Space; Inland.

\section{Introdução}

Esse artigo tem como objeto de estudo saberes e práticas higienistas e eugenistas que circularam e se tornaram parte do processo educativo da Escola Superior de Agricultura e Veterinária (ESAV) entre os anos de 1940 e 1948.

\footnotetext{
${ }^{1}$ Universidade Federal de Viçosa, Viçosa/MG, pedro.milagres@ufv.br.

${ }^{2}$ Universidade Federal de Viçosa, Viçosa/MG, gabriel.g.oliveira@ufv.br.

${ }^{3}$ Universidade Federal de Viçosa, Viçosa/MG, andersonbaia@ufv.br.
} 
A ESAV foi criada em 1920, mediante iniciativa e autorização do presidente Arthur Bernardes ${ }^{4}$, e inaugurada em 1926, na cidade de Viçosa, Minas Gerais. A Escola nasceu como um dos marcos na modernização técnica e pedagógica no ensino agrícola brasileiro, e teve como sustentação a dimensão política da época, a qual estava em estreita relação com as intenções dos setores ruralistas ligados ao desenvolvimento econômico do Estado de Minas Gerais, por meio da produção agrícola (AZEVEDO, 2005).

Sua construção e condução nos primeiros anos foram delegadas ao agrônomo estadunidense Peter Henry Rolfs, que trouxe dos Estados Unidos o modelo de ensino agrícola dos Land Grant Colleges (AZEVEDO, 2005; BAIA, 2006; RIBEIRO, 2006). Esse modelo "representou a demanda da elite agrária brasileira por uma agricultura mais racional e produtiva em consonância com uma moderna concepção pedagógica" de cunho prático e utilitário (CASTRO; ALVES, 2017, p.755) ${ }^{5}$.

Devido à presença de Rolfs e à inspiração em um modelo de ensino agrícola moderno, era comum o trânsito de sujeitos entre a ESAV e as instituições de ensino dos Estados Unidos e da Europa, sendo que alguns destes compuseram o quadro docente nos primeiros anos da instituição (AZEVEDO, 2005; CASTRO; ALVES, 2017).

Naqueles territórios, em finais do século XIX e no início do século XX, circulavam discursos de cunho médico-biológico voltados à higiene, dando origem ao que ficou conhecido como Movimento Higienista (SOARES, 1990) ou Movimento Sanitarista (HOCHMAN, 2012). Partindo dos conhecimentos da Medicina e da Biologia, os higienistas acreditavam que a transmissão das doenças por agentes patológicos invisíveis e a degradante dinâmica de trabalho industrial eram empecilhos à economia das grandes nações. Revestido de um caráter social e preventivo, os saberes produzidos pelos higienistas buscaram intervir no meio e ensinar hábitos de cuidado higiênico à população (GÓIS JUNIOR, 2003).

No Brasil, o pensamento médico-higiênico assumia algumas particularidades devido à ambiência nacional, que comportava uma população predominantemente mestiça e rural. Tais características propiciaram uma ênfase nos espaços rurais e de produção agrícola nos debates

\footnotetext{
${ }^{4}$ Arthur Bernardes (1875-1955) foi um político viçosense, formado em Direito pela Faculdade de São Paulo, em 1900, e ocupou o cargo de presidente do Estado de Minas Gerais entre os anos de 1918 e 1922 . Atualmente, este cargo se refere ao posto de Governador de Estado.

${ }^{5}$ Mais informações sobre o modelo dos Land Grant Colleges, consultar: Ribeiro (2006; 2016).
} 
higienistas, a partir de finais da década de 1920, e uma aproximação, por vezes confusa, com os debates eugenistas que circulavam no país (STEPAN, 2005; GÓIS JUNIOR; GARCIA, 2011; HOCHMAN, 2012).

Discursos eugênicos, especialmente, circularam no Brasil nos primeiros anos do século XX (WEGNER; SOUZA, 2013; SOUZA, 2016). A conformação da raça brasileira, composta pela ampla miscigenação da população indígena, branca e negra, era vista com viés negativo por parte dos intelectuais e médicos da época. Nos discursos dos eugenistas europeus, os povos negros e indígenas foram caracterizados como símbolo das imperfeições, tanto no campo comportamental quanto em sua constituição genética, fato que, segundo Stepan (2005), colocava o país como uma nação fadada ao atraso.

Em detrimento à imagem pessimista dos eugenistas europeus, foi investida, pela intelectualidade brasileira, uma interpretação cautelosamente otimista - e ainda racial - de que a regeneração nacional se daria por meio do saneamento e da higiene dos hábitos. Assim, cada vez mais, as interpretações higienistas ganharam espaço em um país onde as elites sociais acreditavam na regeneração nacional. As interpretações se deslocavam da raça como problema nacional primeiro, para as condições sanitárias e de higiene da população (STEPAN, 2005; HOCHMAN, 2012).

Desta forma, os discursos higiênicos e eugênicos se confluíram, por vezes, nos debates da intelectualidade, tendo a educação moderna e higiênica como possibilidade de construção do país para o progresso econômico e social. Já os espaços rurais se tornam um lugar a ser investido pelos higienistas, tanto na recuperação dos sujeitos, quanto no fortalecimento da produção agrícola (GÓIS JUNIOR, 2014).

Partindo do princípio de que a ESAV foi construída para ser uma instituição de excelência na formação de sujeitos que atuariam na modernização da agricultura em Minas Gerais, mas estava localizada em uma região do interior do Estado, onde saberes e práticas não circulavam como nos grandes centros, surgiram as seguintes questões que nos orientam nesse estudo: Como e quais sujeitos propagavam os saberes e práticas higienistas e eugenistas na ESAV? Como as teorias higienistas e eugenistas aparecem nos discursos veiculados? Qual caráter educativo assumem os discursos circulantes na ESAV? Como a Revista Seiva contribuiu com a formação dos esavianos?

Periódico Horizontes - USF - Itatiba, SP - Brasil - e021062 
A partir dessas questões, traçamos como objetivo desse estudo analisar os saberes e práticas higienistas e eugenistas que circularam na Revista Seiva e que se tornaram parte do processo educativo da Escola Superior de Agricultura e Veterinária (ESAV) entre os anos de 1940 e 1948.

\section{Procedimentos metodológicos}

Esse estudo está ancorado na perspectiva da História Cultural, e nos inspiramos na afirmação de Certeau (2015) de que, em história, tudo começa com o movimento de separar, reunir e transformar em documentos certos objetos distribuídos de outra maneira. Como fonte, utilizamos a Revista Seiva que, segundo Baia (2006), foi um importante veículo de divulgação do pensamento estudantil na ESAV, circulando ideários de alunos, professores e administração da instituição.

Foi consultado um total de 29 exemplares da Revista, os quais são datados entre 1940 e 1948 e estão disponíveis no acervo do Arquivo Central Histórico da Universidade Federal de Viçosa (UFV). O estudo tem como recorte inicial a criação da Revista Seiva, em 1940, e como recorte final a oficialização da alteração da ESAV em 1948, quando passa a atender pelo nome de Universidade Rural do Estado de Minas Gerais (UREMG) e apresentar maior influência do Estado na organização de suas ações.

Fundada em agosto 1940, a Revista Seiva se caracterizou como um órgão oficial do Centro de Estudantes da ESAV, com periodicidade trimestral e sendo dirigida pelos discentes da instituição. O conteúdo veiculado era organizado em quatro colunas (Estudos, Literatura, Esportes e Sociais) que apresentavam artigos, entrevistas e palestras, no formato de ensaios informativos, divulgação, discussão e orientação acerca do conhecimento produzido na instituição, sobretudo, no campo da agricultura e veterinária.

O periódico teve um papel relevante na sedimentação de conhecimentos, costumes, tradições e crenças. Atingiu, inclusive, um amplo alcance, chegando a registrar a publicação de 8.000 exemplares de um dos seus números, circulando no território nacional e em países do exterior (AZEVEDO, 2002).

Para a análise dos saberes e práticas contidos na revista, tomou-se como referencial os 
procedimentos de análise documental apontados por Sá Silva, Almeida e Guindani (2009). Segundo os autores, a análise dos documentos pode ser organizada em quatro etapas: 1. Separação da unidade de análise; 2. Categorização; 3. Revisão das informações extraídas; 4. Novo julgamento das categorias (SÁ SILVA; ALMEIDA; GUINDANI, 2009).

A primeira etapa consiste na separação de todas as unidades correspondentes à temática da pesquisa, sendo este processo realizado na constituição dos documentos. Na segunda etapa, todas as informações do corpo de documentos relacionadas aos conhecimentos higienistas foram agrupadas em três categorias (Projeto de melhoramento racial e sanitário; Condição racial e higiênica do povo brasileiro; Higiene doméstica) por afinidade temática. Para fortalecer as categorias, foram aplicadas as regras preconizadas por Sá Silva, Almeida, Guindani (2009), que são: homogeneidade externa e interna, plausabilidade, coerência e autoexclusão. Por fim, foram executadas as últimas duas etapas, que envolvem a revisão das informações e um novo julgamento das categorias.

As três categorias foram organizadas em uma disposição posta à priori e exploradas por meio de múltiplas combinações e articulações capazes de produzir sentidos a serem narrados (PESAVENTO, 2014). Esta disposição foi construída por meio de uma revisão de literatura sobre o tema, aliada à exploração das fontes, resultando na organização do seguinte enredo: num primeiro momento são analisados os saberes e práticas eugenistas veiculados pela revista, e sua aproximação com intelectuais eugenistas nacionais; já num segundo momento, o estudo se volta para a veiculação do higienismo e sua relação com a instrução de novos sujeitos higienizadores no campo, e; por fim, apresentamos as considerações finais.

\section{"Eugenia" e "seleção genética": a ESAV como uma "uma oficina de ciclopes, uma forja de gigantes"}

A ESAV, desde sua fundação, estava sustentada pela tarefa de orientar a atuação do homem do campo a partir da propagação de conhecimentos científicos e pragmáticos. Por meio da promoção de uma "moderna ciência agrícola", orientada pela racionalização da prática, a 
instituição se colocava como uma "oficina de ciclopes", para formar "gigantes" ${ }^{6}$ (COSTA VAL FILHO, 1943).

Nas páginas de uma de suas edições - revista Seiva - observamos o caráter de dedicação da ESAV ao projeto de desenvolvimento do Brasil, defendendo que "melhorando a semente, o animal e o homem, a ESAV vai cumprindo, por intermédio de seus filhos, o nacionalista programa de intensificar a agricultura racional em todo país onde for chamada a cooperar" (SEIVA, 1943, p.3).

Tornava-se necessário educar por meio de conhecimentos produzidos "cientificamente" e regenerar os braços que sustentam a agricultura nacional, sob égide dos diferentes saberes higienistas e eugenistas que circulam na revista Seiva. Assim, se propaga, de forma explícita, saberes em defesa da Eugenia, além de estabelecer interpretações eugênicas do povo brasileiro e disseminar conhecimentos higiênicos.

Em 1940, o periódico publicou em seu primeiro número uma reportagem intitulada "Eugenia", de autoria do aluno Paulo Armando Newlands, formado nos cursos de Agronomia e Medicina Veterinária neste mesmo ano. Este escrevia nas páginas do periódico sobre a Eugenia, apontando a necessidade de compreendê-la enquanto uma "ciência nova", apresentando intelectuais que estudavam o tema, como George Mendel (1822-1884) e Octávio Domingues (1897-1972).

Segundo Del Cont (2008), Mendel era um dos principais defensores da tese da hereditariedade, na qual os caracteres genéticos dos pais eram transmitidos às futuras gerações. Nesse sentido, seus achados inspiraram técnicas de intervenção radical de controle da reprodução humana e da miscigenação em países como os Estados Unidos. Souza (2016) e Wegner (2017) nos mostram que, no Brasil, suas apropriações se deram de forma menos intensa e com diferentes sentidos, dando bases ao pensamento eugênico no país, especialmente em sua vertente negativa ${ }^{7}$.

\footnotetext{
${ }^{6} \mathrm{Na}$ mitologia grega, ciclopes eram gigantes que trabalhavam forjando os raios a serem utilizados por Zeus. A ESAV, portanto, formaria os "gigantes" que, em sua atuação no campo, fortaleceriam a agricultura do Estado, contribuindo com o desenvolvimento do país.

${ }^{7}$ A eugenia negativa baseou-se nas concepções do determinismo genético de Francis Galton e sua marca estava na postura intervencionista do Estado, pautado no fator raça. Seus intelectuais defendiam que os portadores dos melhores caracteres genéticos deveriam ser estimulados a se reproduzir, assim como deveria ser evitada a reprodução de sujeitos degenerados, por meio de técnicas de segregação, esterilização e controle dos casamentos (GÓIS JUNIOR ; GARCIA, 2011; WEGNER; SOUZA, 2013). No Brasil, tivemos como um dos principais expositores desta vertente o autodeclarado eugenista Renato Kehl.
}

Periódico Horizontes - USF - Itatiba, SP - Brasil - e021062 
Um dos defensores da tese mendeliana no Brasil foi o zootecnista e geneticista Octávio Domingues ${ }^{8}$ que, mesmo adepto ao mendelismo ${ }^{9}$, protagonizou o que Stepan (2005) chamou de "eugenia latina", ou então, positiva. Para a autora, esta vertente mantinha o seu caráter racial, alimentada por uma crença no mito do embranquecimento do povo brasileiro, contudo, se distinguia da negativa pelo enfoque na produção de uma consciência eugênica por meio da educação dos indivíduos, ao contrário das intervenções radicais (STEPAN, 2005; GÓIS JUNIOR; GARCIA, 2011).

O posicionamento de Octávio Domingues, por vezes, tendenciava-o a um eugenismo mais radical, embora optasse pela defesa de uma eugenia mais voluntária e menos autoritária. Conforme aponta Stepan (2005), Domingues defendia que o cruzamento de diferentes raças, como na mestiçagem brasileira, era plenamente saudável, e que a eugenia deveria ser realizada por vias educativas para a promoção de uma consciência eugênica voluntária, sem a presença coercitiva do Estado. Para isso, com base em seus estudos com plantas e animais, sugeriu o aproveitamento das leis de melhoramento genético para a reprodução humana (WEGNER, 2017).

O zootecnista e geneticista manteve estreitas relações com o ensino agrícola brasileiro, lecionando na Escola Superior de Agronomia Luiz de Queiroz (ESALQ) ${ }^{10}$, onde direcionou seus estudos. Seu pensamento eugênico aparece de forma influente nos conhecimentos veiculados pela revista estudantil da ESAV, numa instituição comprometida com o melhoramento dos homens e mulheres do campo.

Assim, o artigo publicado pelo aluno Paulo Armando Newlands, logo no primeiro número e na abertura da coluna de Estudos, dá um lugar de destaque a estes intelectuais, garantindo o

\footnotetext{
${ }^{8}$ Octávio Domingues foi formado pela Escola Superior de Agricultura Luiz de Queiroz (ESALQ) na cidade de Piracicaba, em 1917, e atuou pela mesma instituição como professor, a partir da segunda década do século XX. O zoólogo acreano teve grande influência sobre o pensamento eugênico nacional e destaque pelos seus estudos com boi Zebu. Era marca de seu pensamento a indissociabilidade entre a Genética e a Eugenia (WEGNER, 2017).

${ }^{9}$ Stepan (2005) aponta que o pensamento eugênico na América Latina conservou bases neolamarckistas, que acreditava na transmissão de caracteres adquiridos pelo meio. Esta tese, muito criticada pelos mendelistas, foi o que permitiu a difusão de uma visão eugênica mais otimista, que acreditava em uma eugenia "preventiva" a partir da limpeza dos maus fatores à saúde. Assim, por mais que Stepan (2005) localize Octávio Domingues neste bojo de intelectuais, Wegner (2017) demonstra que o geneticista foi um adepto do mendelismo e, assim como outros eugenistas brasileiros, compartilhava de muitas características da eugenia de base lamarckista.

${ }^{10} \mathrm{~A}$ ESALQ atualmente está situada na cidade de Piracicaba, no estado de São Paulo. Foi fundada no ano de 1901, sendo uma das referências de escola agrícola em âmbito nacional. A instituição manteve relações diretas e indiretas com a ESAV, sendo, inclusive, uma referência para a construção desta última.
} 
caráter científico e moderno dos saberes eugênicos. No texto, Newlands faz um apelo à formação de uma consciência eugênica e demonstra apreço por técnicas radicais, como o exame prénupcial não-oficial, feito pelo médico da família:

O que se tem em vista é, então, evitar o abaixamento da média, pela reprodução em larga escala da escória humana, perpetuando suas taras, seus defeitos, e, constituindo, sempre, em peso morto para a sociedade. [...] E que maior desgraça pode achar um par, do que ter uma prole alimentadora de hospitais, manicômios, reformatórios? (NEWLANDS, 1940, p.5).

A defesa pelo controle da reprodução, almejando eliminar a livre reprodução dos denominados "escória humana", é uma preocupação apontada por Newlands, que sustenta seus escritos citando o livro Biologia Educacional: noções fundamentais ${ }^{11}$, de Almeida Júnior, publicado em 1939. Nesta obra, ao mencionar a legislação eugênica na Alemanha, são mostrados os grupos humanos a serem castrados no país ${ }^{12}$, além de sugerir a existência de pesquisas que mostram a maior reprodução entre casais oligofrênicos. Paulo Newlands circula a imagem dos "indesejáveis" como maléficos à sociedade, necessitando terem sua reprodução impedida.

Se analisarmos os escritos de Newlands que circularam na Revista Seiva, disseminando o pensamento da época, podemos citar os escritos de Monteiro Lobato ${ }^{13}$, em seu livro Urupês. Apesar de Monteiro Lobato não aparecer nas páginas da Revista Seiva, a categoria da "escória humana", presente em sua obra, é expandida aos caboclos, que são caracterizados enquanto pragas que atrasam o crescimento agrícola no campo (LOBATO, 2007).

Conforme Silveira (2016), a imagem do Jeca Tatu foi influente para a intelectualidade da época, levando à produção de uma imagem fatalista sobre os sujeitos rurais do Brasil. Imbuído da ideia de uma procriação desenfreada e sucessão dos maus fatores, Lobato $(2007$, p.161)

\footnotetext{
${ }^{11}$ A obra se prestou em fornecer saberes sobre saúde e educação a serem levados a professores e alunos aos lugares mais distantes do Brasil, sendo elementos centrais da obra as noções eugênicas e eutécnicas (MORANDO; SOUZA, 2019).

${ }^{12}$ Está nesse grupo: a) Oligofrênicos congênitos ou hereditários; 2) Esquizofrênicos; 3) Loucos, maníacos, depressivos; 4) Epilépticos hereditários; 5) Portadores da doença de Huntington; 6) Cegos hereditários; 7) Surdos hereditários; 8) Portadores de deformidades graves hereditárias; 9) Tendência alcoólica hereditária (ALMEIDA JÚNIOR, 1939, apud. NEWLANDS, 1940).

${ }^{13} \mathrm{O}$ autor brasileiro é conhecido por ter se dedicado a descrever os homens rurais, a partir da segunda década do século XX. No entanto, suas reflexões passam por dois momentos. No primeiro, com a publicação do livro Urupês, em 1914, Lobato fundou a noção de Jeca Tatu, alimentando um pessimismo acerca dos homens rurais. Já no segundo momento, inaugurado com o livro Problema Vital, em 1918, o autor assume uma posição mais otimista ao se aproximar do higienismo, a partir do contato com os estudos de Belisário Penna (SILVEIRA, 2016).
} 
afirma em sua obra que:

Chegam silenciosamente, ele [caboclo] e a 'sarcopata' fêmea, esta com um filhote no útero, outro ao peito, outro de sete anos a ourela da saia - este já de pintinho na boca e faca à cinta. Completam o rancho um cachorro sarnento Brinquinho, a foice, a enxada, a pica-pau, o pilãozinho de sal, a panela de barro, um santo encardido, três galinhas pevas e um galo índio. Com estes simples ingredientes, o fazedor de sapezeiros [caboclo] perpetua a espécie e a obra de esterilização iniciada pelos antigos avós.

Esta visão das "escórias" do progresso humano, que se perpetuam e se reproduzem desenfreadamente, cria uma representação eugênica daqueles que são um atraso e precisam ser controlados. De forma similar, o estudante esaviano se aproxima desta associação ao sugerir a existência de sujeitos que são entraves ao progresso nacional e que se perpetuam desenfreadamente, de geração a geração. Com isto, se ancora no pensamento eugênico ora circulante no país, clamando aos leitores a adesão de suas práticas ditas modernas, já que "é um fato evidente que a sociedade procura melhorar-se; mas ela só conseguirá isto duradouramente, usando os métodos eugênicos" (NEWLANDS, 1940, p.6).

Discurso semelhante ao de Paulo Armando Newlands pode ser encontrado no artigo "Seleção Genética", publicado em 1940 na Revista Seiva. O texto de Eduardo Hugo Frota, formado em 1942 na turma de Engenheiros Agrônomos e Técnicos Agrícolas, expõe a posição do aluno sobre as raças brasileiras.

Observa-se comparações entre as combinações favoráveis na agricultura e na veterinária para uma melhor produção de plantas e animais, se valendo, como ilustração, de uma analogia com a reprodução humana. Para ele, a combinação das raças "portuguesas", "negras" e "nativas" no Brasil resultou em uma diversidade de fisionomias que, sendo bem administrada, iria possibilitar uma nova raça. Conforme explica o aluno "[...] a possibilidade de formação de uma nova raça, no dizer de Gunther Just, baseia-se nos três princípios seguintes: mutação, combinação favoráveis de certos fatores e seleção dos produtos que resultam intrinsecamente, dessas boas combinações" (FROTA, 1940, p.12).

O esaviano compartilha da ideia otimista da mestiçagem defendida por Octávio Domingues. Divergindo de importantes nomes que se inspiravam na genética mendeliana, Domingues defendia que, por meio do cruzamento das diferentes raças no Brasil, seria possível 
melhorar a população brasileira e evitar o aparecimento dos degenerados. Ele acreditava que o cruzamento entre as diferentes raças resultaria em um processo de adaptação biológica, gerando uma nova civilização a partir da perpetuação dos caracteres fortes. No entanto, para o eugenista, este processo deveria se dar não pela regulamentação das combinações, e sim pelo investimento em uma educação eugênica da população, levando à adesão voluntária (STEFANO, 2004; STEPAN, 2005; WEGNER, 2017).

Assim sendo, o aluno Eduardo Hugo Frota não se vale apenas das ideias eugênicas de Octávio Domingues sobre a mestiçagem, uma vez que, tal como o zootecnista e geneticista, o aluno esaviano também busca produzir uma consciência eugênica nos leitores a partir da associação entre o cruzamento genético de plantas e animais e a reprodução humana - tendo em vista que a revista se direciona aos espaços de produção agrícola. Todavia, demonstrando uma certa simpatia pelas intervenções mais radicais e indo de encontro ao caráter voluntário, o aluno sugere uma aplicação incisiva da técnica eugênica de regulamentação dos cruzamentos, visando a seleção dos "melhores física e moralmente" e indo "de encontro ao ultra sentimentalismo do nosso povo" (FROTA, 1940, p.12).

Para além dos saberes e práticas voltados à reprodução humana, são colocados em circulação outros conhecimentos capazes de contribuir para a regeneração racial dos sujeitos. Logo no início da revista, no artigo de Newlands, é sinalizada a existência de práticas paralelas à Eugênia, visando o aprimoramento intelectual e físico dos sujeitos já nascidos. O aluno denomina estas práticas de Eutecnia, e atribui a elas a seguinte explicação: "Quando se trata de melhoramento, quer físico quer intelectual, na geração já existente, temos a eutecnia, constatando da higiene, pericultura, Educação Física, etc. De um modo geral, o melhoramento do meio pertence a eutecnia, e o da hereditariedade à eugenia" (NEWLANDS, 1940, p.4).

O aluno evidencia o local ocupado pela Eutecnia enquanto um mecanismo auxiliar às práticas eugênicas. Essa definição trazida por Newlands afasta-o de pensamento evolutivo dos neolamarckistas, que sustentavam a ideia de que os caracteres físicos e intelectuais adquiridos do meio poderiam aprimorar a raça e serem passados às gerações futuras (SOUZA, 2016). Assim, o aluno indica que por meio da atuação direta no meio ambiente e nos corpos, sendo a Educação Física uma das formas de intervenção, a Eutecnia promoveria, ao menos, um bom ambiente para o desenvolvimento da geração nascida, já que esta não poderia ter sua composição racial 
melhorada (SILVA, 2012).

Conforme Silva (2012), este termo aparece no livro Lições de Eugenia, de Renato Kehl, na edição de 1929, como forma de diferenciar as ações de ordem "parcinéticas", que melhoram o ambiente e a vida dos indivíduos, mas não influem sobre a individualidade genética (KEHL, 1935 apud SILVA, 2012). O termo fez parte de consecutivas tentativas inconformadas do eugenista em diferenciar as ações de ordem higiênica das eugênicas, mostrando que a primeira não poderia melhorar o estoque hereditário no Brasil (STEPAN, 2005).

Assim, o aluno Paulo Newlands demonstra, por meio do artigo, uma aproximação com os eugenistas de inspiração mendeliana, os quais buscavam distinguir as práticas que não poderiam aperfeiçoar a raça, porém, sem desconsiderar sua importância dentro do projeto de crescimento nacional.

Apesar do esforço de diferenciação entre práticas higiênicas e eugênicas feitas no primeiro artigo, a tentativa de demarcar uma visão eugênica propriamente mendelista para pensar as práticas de Educação Física e educação higiênica não se repete na revista estudantil. Logo, o conceito de Eutecnia não reincide em outros momentos no periódico, e os saberes ligados à Educação do corpo aparecem como capazes de promover transformações eugênicas, se aproximando das proposições da "eugenia latina", de base predominantemente neolamarckista. Em um caráter educacional, eram apontados aos alunos esavianos noções acerca da importância das práticas de educação física na modelação do plasma genético, e suas responsabilidades na educação higiênica do campo, indispensável à recuperação eugênica e progresso nacional.

Nos textos presentes na Revista Seiva fica evidente a preocupação frente à constituição da população brasileira, trazendo em evidência técnicas eugênicas que se propunham a contribuir com essa linha de pensamento. Controle dos casamentos para evitar proliferação dos caracteres genéticos ruins ou degenerados (NEWLANDS, 1940), combinações de casais para construção de novas raças (FROTA, 1940), lavagem vaginal para definição do sexo da prole (tanto em humanos como em animais) (WARREN, 1941) e práticas de educação física e educação higiênica (NEWLANDS, 1940) eram expostos na revista como forma de educar o público leitor na instituição, comprometidos com a regeneração dos espaços rurais brasileiros. 
"Educar este grande povo, higienizar este grande povo"

A Revista Seiva veicula uma imagem de instituição preocupada em modernizar os espaços agrários brasileiros. Incluía, nesse processo, o investimento na educação higiênica dos corpos que ocupam o interior do país. Tendo em vista a caracterização do povo do campo em más condições sanitárias e de saúde, formar engenheiros agrônomos capazes de educar os sujeitos implicava, diretamente, em higienizá-los. Da mesma forma, os "caboclos" sairiam da condição de degenerados para tornarem-se "agentes higiênicos".

Atribuindo um papel de destaque aos esavianos, a Revista evidencia os problemas sociais da população rural brasileira, sugerindo os conhecimentos científicos como adequados para intervir nessa realidade. Tais discursos se aproximam dos debates promovidos por Monteiro Lobato e Belisário Penna, que apontam os problemas disgênicos e o estado de abandono em que vivem essa população no interior do Brasil. Tornava-se importante, naquele momento, pensar em estratégias que contribuíssem para a recuperação destes homens e mulheres do campo, pois, antes de se pensar o melhoramento agrícola no país, "urge que se faça o melhoramento do meio [rural] e o melhoramento e adaptação das raças" (LANA, 1944, p.32).

Logo, se estabelecem narrativas na revista que apontam os rurais como carentes de educação, higiene e saneamento, sendo que estes não deveriam ser ignorados pelos esavianos. Como se expressa, o maior impacto desta condição de falta estava no Êxodo Rural.

[...] Sem dúvidas alguma é um assunto que está tomando vulto [êxodo rural], e sua importância é maior do que se pensa realmente. Basta verificar a desastrosa situação em que está passando o país, pela queda da produção, que por sua vez está diretamente ligado com a saída dos homens do campo [...]. Na roça o pobre caboclo tem a malária e a verminose como companheiros; se precisa de médico, tem que desembolsar no mínimo 'duzentos cruzeiros', quando consegue uma condução para os mesmos; a carestia das drogas é de assombrar. O nosso pobre homem, vai então procurar raizeiras, que aumentam-lhe ainda mais o mal com torpeões. A sua casa de morada é tapume barreado, coberto de sapé, no qual o vento e a chuva adentram livremente; as chupanças, percevejos encontram ali seu paraíso. A instalação sanitária é a bananeira mais perto da casa ou mesmo atrás dessa. [...] E não é para se admirar que eles adotem a filosofia do 'pra quê se esforçar' e encontram o consolo na branquinha (MOREIRA, 1946, p.16).

Além do êxodo rural, que resulta das más condições de assistência sanitária e educacional 
do povo no campo, outro problema estava em refugiar-se nos vícios, que nada contribuem para

o desenvolvimento da raça. Contudo, os comportamentos desordeiros não permaneceram apenas reclusos e destinados à responsabilidade individual, mas sim, precisavam ser combatidos pelo Estado por meio do controle higiênico da população e com o melhoramento das condições sanitárias (PEIXOTO, 2017).

A ESAV, assim, se colocava enquanto uma instituição preocupada em formar agentes de solução destas demandas do meio agrário. Ela parecia elencar em seu sistema formativo a preocupação com as condições de vida do homem que vivia no campo e sua família, visto que estas informações eram largamente divulgadas pelos alunos por meio da revista Seiva. Nos discursos de formatura veiculados em suas páginas, a Escola procurou mostrar aos alunos que uma de suas missões, carregando o "espírito" esaviano, era o exercício da função higiênica no interior do país, tornando-se verdadeiros agentes higienizadores. Tomamos como exemplo os votos do embaixador americano Jefferson Caffery à turma de formandos na ESAV, em 1942:

\begin{abstract}
Será, também, vossa responsabilidade e vosso dever, auxiliar os vossos governos e as vossas instituições no trabalho que tão habilmente veem empreendendo nas esferas humanas e socias, para proteger e promover o bemestar de vossa maior riqueza - o povo de Minas Gerais. Esses empreendimentos enquadram as medidas tomadas no que diz respeito à educação, saúde, saneamento e nutrição. [...] No campo da saúde, do saneamento e da nutrição encontram-se bases essenciais para a felicidade e prosperidade de um povo. Mens sana in corpore sano (FESTA..., 1943, p.49-50).
\end{abstract}

Diante da falta de instituições destinadas à formação do homem do campo, cabe aos alunos a missão de salvar este homem e o meio agrário nacional, tendo como base os conhecimentos científicos adquiridos na Escola. Dentre seus serviços para o interior, estava a missão de levar "os preceitos de higiene humana e veterinária" e o "melhoramento das suas condições de vida".

A expressão Mens sana in corpore sano, que finaliza o trecho destacado anteriormente, apareceu como uma das máximas higienistas daquela época e, por finalidade, atribuía uma relação causal direta entre uma mente sã e um corpo são. Em outras palavras, para se ter uma população com aspectos morais positivos, era necessário investir em corpos livres de enfermidades e vícios. Para isso, parte-se da tríade spenseriana de uma educação intelectual, 
moral e física que, para além de instruir os corpos, orientava sobre a necessidade de educá-los a partir de um processo de reconstrução dos hábitos (VAGO, 2002).

Assim, fazia-se pertinente instruir práticas individuais no meio agrário, ligadas aos hábitos de cuidado doméstico, dos filhos, dos cuidados da moradia e dos viveiros de animais. Os esavianos, por sua vez, aparecem enquanto importantes agentes de intervenção na vida no campo, protegendo os sujeitos das enfermidades e, por conseguinte, auxiliando na ampliação da produção. O dever dos formados na ESAV pode ser percebido a seguir:

\begin{abstract}
Esses rapazes que saem dessa Escola e vão para as fazendas, devem pensar nesse problema e procurar resolver pelo menos a parte que lhe cabe. Em $1^{\circ}$ lugar construir fossas com as dejeções, afastando assim o amarelão. Procurar drenar ou desinfetar com verde paris ou querosene, as águas estagnadas perto das moradias, ninho das anófeles [...]. E na medida do possível ir eliminando os mocambos por casas decentes. [...] A água para se beber, deve também merecer atenção do proprietário, limpando as minas fazendo capitação ou levando-a encanada (MOREIRA, 1946, p.17).
\end{abstract}

Os esavianos formados pela instituição são instruídos a exercer intervenções higienistas destinadas a desenvolver, junto aos fazendeiros, estruturas sanitárias para afastar insetos propagadores de doenças e parasitas. Ao mesmo tempo, devem realizar a assepsia das moradias, tornando-as limpas e adequadas aos valores morais, ou seja, "decente". Desta forma, a atuação dos Engenheiros Agrônomos, na impulsão da economia de Minas Gerais e do Brasil, por meio da agricultura, deveria ser antecedida pela tarefa de melhoramento dos sujeitos rurais e de suas moradias.

Além de contribuir com a impulsão da produção agrária nacional, a ESAV lançava aos seus alunos a missão de educar os homens do campo e, como higienistas, melhorar a saúde individual e coletiva dessa população. Em outras palavras, eram mobilizados a uma cruzada "dedicada para acordar as rachãs da pátria brasileira" (MOREIRA, 1946, p.17).

Mais que apenas intervir nas condições básicas da vida no campo por meio das ações práticas, os esavianos assumem, tal como em Gondra (2003), a função social de promover a educação e intervenção no meio, visando a produção de sujeitos higienizadores e capazes de higienizar seu próprio meio. Nela, a matriz médico-higiênica passa a guiar as ações de reestruturação dos espaços, na relação entre sujeitos e natureza, contribuindo com a chegada 
do projeto higienista nos espaços rurais do Brasil (GONDRA, 2003).

Por meio da revista foi possível perceber que, junto à caracterização dos problemas do campo e dos rurais, eram estampados conhecimentos higiênicos que instruíam seus leitores quanto à emergência da mudança de infraestrutura e dos hábitos dos rurais. Além disso, foi observado que o momento destinado a celebrar a certificação dos profissionais que irão atuar na sociedade, enquanto técnicos e engenheiros agrícolas, é utilizado como espaço para demarcar sua missão higiênica no campo.

Portanto, ao suscitar problemas do campo oriundos da precariedade nas condições sanitárias e higiênicas, o que acomete a raça, a revista veicula uma imagem dos esavianos como sujeitos capacitados a educar e higienizar a população do campo, contribuindo, assim, para o aprimoramento da saúde e da raça nos espaços mais desassistidos.

\section{Considerações finais}

A ESAV foi uma importante instituição estabelecida no interior do Estado de Minas Gerias, tendo por finalidade contribuir para o desenvolvimento e modernização dos espaços rurais do Estado e do Brasil. Saberes e práticas higienistas e eugenistas faziam parte das pretensões de educar os sujeitos rurais para o melhoramento do meio, tendo a revista Seiva como importante veículo de circulação na última década de funcionamento da ESAV, até sua transformação em UREMG.

Nas páginas da revista, alunos e ex-alunos tinham espaço para difundir as teorias por meio de artigos científicos, pequenas instruções e discursos proferidos nos eventos de formatura. Dentre os atores, aparecem alunos como Paulo Newlands, Eduardo Hugo Frota, Orodovaldo Moreira, Joaquim Campos, Clarimundo Campos e o ex-aluno Manoel da Costa Lana. Além destes, intelectuais de renome no campo eugênico, como Octávio Domingues, Almeida Junior e George Mendel, têm suas ideias citadas na revista.

Os alunos e ex-aluno mencionados anteriormente, junto a outros que contribuíram, circularam na revista estudantil conhecimentos eugênicos que se aproximavam, predominante, de uma "eugenia latina". Esta se apresentava aos eugenistas como uma vertente positiva ligada às práticas higienistas, a qual permitiria aos esavianos contribuir para o melhoramento da raça 
por meio da intervenção na natureza e nos hábitos dos rurais. Já a vertente negativa, por sua vez, parece tentar se estabelecer inicialmente na revista, porém, sem sucesso.

A eugenia negativa se fez presente em discursos que desestimulavam a reprodução de determinados indivíduos. Práticas como o incentivo à lavagem vaginal para escolha da prole, o controle matrimonial de forma não-oficial e administrado pela família, e a seleção das combinações genéticas mais favoráveis às gerações vindouras, veiculavam práticas eugênicas mais radicais. Além disso, é mencionada a Eutecnia (na forma de Higiene e Educação Física) como uma técnica que contribui para o melhoramento das condições atuais, sem melhorar as próximas gerações.

Já a vertente positiva, de uma "eugenia latina", apareceu com maior ênfase no decorrer dos números impressos, sendo veiculada junto a discursos higienistas que, por vezes, incutiam nos alunos a missão de melhorar os "homens" rurais a partir da intervenção sanitária e instrução higiênica. Práticas higienistas que ensinam sobre os cuidados com os alimentos, limpeza e sanitarização da habitação, assim como de combate às pragas da lavoura, como saúva e ervas daninhas, aparecem com ênfase na revista.

Além disso, os esavianos eram ensinados e instruídos quanto aos benefícios das práticas de educação física para o aprimoramento do corpo e de suas capacidades úteis às gerações vindouras, promovendo, também, o aperfeiçoamento moral e do intelecto. Assim, se fazia necessário formar alunos exemplares em suas capacidades físicas e morais, de forma que eles pudessem propagar valores higiênicos na superação dos problemas do campo, melhorando a raça.

A revista Seiva participa do processo formativo dos esavianos reforçando saberes higiênicos e eugênicos, incentivando-os a intervir sobre seus hábitos e os dos sujeitos rurais e seu meio, como agentes higienizadores. Como o periódico possuía considerável número de tiragens e tinha a finalidade de veicular conhecimentos de interesse aos fazendeiros, alcançando significativo público nas fazendas de Minas Gerais e de outros estados, difundindo pelo interior formas de higienizar e eugenizar o campo. Por ser uma revista institucional, demarca também aos leitores uma formação científica e moderna na ESAV, a qual capacita e conscientiza administradores rurais, técnicos e engenheiros agrícolas acerca das necessidades do campo, definindo aos esavianos formados e à instituição um importante lugar na vida social do interior brasileiro. 
Portanto, tendo em vista a presença de discursos higienistas e eugenistas em circulação por meio de um periódico estudantil institucional de uma Escola Superior no interior de Minas Gerais, em um recorte em que parte da literatura existente aponta a superação destes conhecimentos no Brasil, faz-se necessário o investimento em novos estudos que ampliem a sua compreensão e o panorama da sua manifestação.

\section{Referências}

AZEVEDO, D. S. Estudo comparado dos periódicos Ceres e Seiva, como fontes da história da educação da Universidade Federal de Viçosa. In: CONGRESSO BRASILEIRO DE HISTÓRIA DA EDUCAÇÃO, 2., 2002, Natal. Anais [...]. Natal: Núcleo de Arte e Cultura, 2002. p.1-10.

AZEVEDO, D. S. Melhoramento do homem, do animal e da semente: o projeto político pedagógico da ESAV (1920-1948), organização e funcionamento. 2005. 225f. Tese (Doutorado em Educação) - Universidade de São Paulo, São Paulo, 2005.

BAIA, A. C. O esporte na consolidação e propagação do espírito esaviano. 2006. $144 \mathrm{f}$.

Dissertação (Mestrado em Educação) - Universidade Federal de Uberlândia, Uberlândia, 2006.

CASTRO, M. G.; ALVES, D. A. Ensino, pesquisa e extensão na Universidade Federal de Viçosa: origem e trajetória institucional (1926-1988). Revista Brasileira de Educação, Rio de Janeiro, v.22, n.70, p.752-773, jul. 2017.

CERTEAU, M. A escrita da história. Trad. Maria de Lourdes Menezes. 3. ed. Rio de Janeiro: Forense, 2015.

COSTA VAL FILHO, J. B. Noite Molhada. Revista Seiva, Viçosa, n.11, p.24-25, 1943.

DEL CONT, V. Francis Galton: eugenia e hereditariedade. Scientiae Studia, São Paulo, v.6, n.2, p.201-218, jun.2008.

FESTA de formatura na ESAV - 15 de Dezembro de 1942. Revista Seiva, Viçosa, n.12, p.44-50, 1940.

FROTA, E. H. A seleção genética. Revista Seiva, Viçosa, n.2, p.12-14, 1940.

GÓIS JUNIOR, E. Alberto Torres e os higienistas: intervenção do Estado na educação do corpo (1910-1930). Saúde e Sociedade, São Paulo, v.23, n.4, p.1445-1457, dez. 2014.

GÓIS JUNIOR, E.; GARCIA, A. B. A eugenia em periódicos da educação física brasileira (19301940). Revista da Educação Física/UEM, Maringá, v.22, n.2, p.247-254, jul. 2011. 
GÓIS JUNIOR, E. O século da higiene: uma história de intelectuais da saúde (Brasil, século XX). 2003. 303f. Tese (Doutorado em Educação Física) - Universidade Gama Filho, Rio de Janeiro, 2003.

GONDRA, J. G. Homo hygienicus: educação, higiene e a reinvenção do homem. Cadernos Cedes, Campinas, v.23, n.59, p.25-38, abr. 2003.

HOCHMAN, G. A era do saneamento. 3. ed. São Paulo: Hucitec, 2012.

LANA, M. L. Discurso do paraninfo da turma de técnicos agrícolas de 1943. Revista Seiva, Viçosa, n.15, p.31-34, 1944.

LOBATO, M. Urupês. São Paulo: Editora Globo, 2007.

MORANDO, A.; SOUZA, N. G. S. A biologia educacional e a higiene escolar na década de 1940: a (in)visibilidade das diferenças na educação brasileira. Textura, Canoas, v.21, n.46, p.4-23, jun. 2019.

MOREIRA, O. A. Êxodo rural. Revista Seiva, Viçosa, n.23, p.16-18, 1946.

NEWLANDS, P. A. Eugenia. Revista Seiva, Viçosa, n.1, p.4-8, 1940.

PEIXOTO, P. B. Até que a eugenia nos separe: raça, saúde e a proposta do exame médico prénupcial no Brasil (1918- 1936). 2017. 205f. Dissertação (Mestrado em História) - Universidade Estadual Paulista "Júlio de Mesquita Filho", Franca, 2017.

PESAVENTO, S. J. História \& história cultural. 3. ed. Belo Horizonte: Autêntica, 2014.

RIBEIRO, M. G. A educação superior norte-americana: gênese de um modelo. História da Educação, Porto Alegre, n.48, p.75-93, 2016.

RIBEIRO, M. G. Caubóis e caipiras: os land grant colleges e a Escola Superior de Agricultura de Viçosa. História da Educação, Pelotas, n.19, p.105-120, 2006.

SÁ-SILVA, J. R.; ALMEIDA, C. D.; GUINDANI, J. F. Pesquisa documental: pistas teóricas e metodológicas. Rev.Bras. de História \& Ciências Sociais. n.1, p.1-15, jul., 2009.

SEIVA. Viçosa: [s.n.], v.3, n.12, jun. 1943.

SILVA, A. L. S. Nos domínios do corpo e da espécie: eugenia e biotipologia na constituição disciplinar da educação física. 2012. 261f. Tese (Doutorado em Ciências do Movimento) Universidade Estadual do Rio Grande do Sul, Porto Alegre, 2012.

SILVEIRA, É. A cura da raça: eugenia e higienismo no discurso médico sul-rio-grangense nas primeiras décadas do século XX. Porto Alegre: Editora da UFCSPA, 2016. 
SOARES, C. L. O pensamento médico-higienista e a educação física no Brasil: 1850-1930. 1990. 256f. Tese (Doutorado em Educação) -Pontifícia Universidade Católica de São Paulo, São Paulo, 1990.

SOUZA, V. S. A eugenia brasileira e suas conexões internacionais: uma análise a partir das controvérsias entre Renato Kehl e Edgard Roquette-Pinto, 1920-1930. História, Ciências, Saúde - Manguinhos, Rio de Janeiro, v.23, p.93-110, dez. 2016.

STEFANO, W. Relações entre eugenia e genética mendeliana no Brasil: Octávio Domingues. In: MARTINS, R. A. et al. (ed.). Filosofia e história da ciência no Cone Sul: 3o encontro. Campinas: Afhic, 2004. p.486-495.

STEPAN, N. L. A hora da eugenia: raça, gênero e nação na América Latina. Rio de Janeiro: Editora Fiocruz, 2005.

VAGO, T. M. Cultura escolar, cultivo de corpos: educação physica e gymnastica como práticas constitutivas dos corpos de crianças no ensino público primário de Belo Horizonte (1906-1920). Bragança Paulista: Edusf, 2002.

WARREN, C. O controlo do sexo é uma realidade científica. Revista Seiva, Viçosa, n.4, p.15-16, 1941.

WEGNER, R. Dois geneticistas e a miscigenação. Varia História, Belo Horizonte, v.33, n.61, p.79107, abr. 2017.

WEGNER, R.; SOUZA, V. S. Eugenia 'negativa', psiquiatria e catolicismo: embates em torno da esterilização eugênica no Brasil. História, Ciências, Saúde - Manguinhos, Rio de Janeiro, v.20, n.1, p.263-288, mar. 2013.

Recebido em abril 2021.

Aprovado em setembro 2021. 